\title{
Preliminary characterization and inhibitory activity of bacteriocin like substances from Lactobacillus casei against multi-drug resistant bacteria
}

\author{
Farzana Binte Hasan ${ }^{1}$, Mahin Reza $^{2}$, H. M. Abdullah Al Masud ${ }^{1}$, Md. Kamal Uddin ${ }^{1}$, Mohammad Seraj Uddin*1 \\ ${ }^{1}$ Department of Microbiology, University of Chittagong, Chattogram-4331, Bangladesh; ${ }^{2}$ Department of Microbiology, Noakhali Science and Technology University, \\ Noakhali-3814, Bangladesh
}

\begin{abstract}
Antimicrobial resistance is a mounting threat to the control of infectious diseases worldwide. Due to the increasing rate of drug resistance, there is continuous requirement for new and safe antimicrobial agents both for therapeutic purposes and food industries. The potential of bacteriocin has attracted much attention in recent years. We characterized bacteriocin like substances produced by Lactobacillus casei. This bacterium produces bacteriocin like substances that have the ability to inhibit multi-drug resistant pathogenic bacteria such as Staphylococcus aureus, Klebsiella pneumoniae, and Proteus vulgaris. To investigate the antimicrobial property of the bacteriocin like substances produced by L.casei, cell free supernatant (CFS) was prepared and antagonistic activity of cell free supernatant was determined by agar well diffusion method. Production of bacteriocin like substances was greatly affected by nutrient media, $\mathrm{pH}$, temperature and incubation period. Highest inhibitory activity was observed when L.casei was grown in MRS broth (De Man, Rogosa and Sharpe broth) (pH 4.0) for 72 hoursat $37^{\circ} \mathrm{C}$. The active components of CFS responsible for antagonistic activity are proteinaceous in nature since they are susceptible to heat treatment. Partial purification of this CFS was done by organic solvent extraction method. Among the eight isolates tested, only $S$. auereus, Proteus vulgaris and $K$. pneumoniae showed more sensitivity to the partially purified crude bacteriocin like substances (CBLS) than CFS.
\end{abstract}

Keywords: Bacteriocin, Lactobacillus casei, multi-drug resistant bacteria, urinary catheter, urinary infection,

\section{Introduction}

Emergence of antibiotic resistance has become a serious threat to human and animal health. This is largely attributed to extensive and improper use of antibiotics, especially in developing countries, where regulations and drug policies are not stringently controlled. The Infectious Disease Society of America (IDSA) reported that approximately $70 \%$ pathogens will become resistant to at least one of the drugs used to treat infection caused by them ${ }^{1}$. Urinary catheters pose a risk of recurring infections in patients suffering from urinary tract infections (UTIs) as they provide an adhering surface for potential urogenital pathogens to form biofilms. These infections are characterized by a poor response to antibiotic therapy and recurrence of infections. The problems associated in managements of these infections with drug resistant pathogens have prompted research focusing on finding alternative therapeutics. Antibiotic resistance in Gram-negative uropathogens is a major global concern having major implications for urological practice, particularly in relation to catheter-associated urinary tract infections (UTIs) and infectious complications following transrectal-ultrasonography-guided biopsy of the prostate or urological surgery ${ }^{2}$.

Bacteriocins, anti-microbial peptides (AMPs) produced by bacteria, are produced by both Gram positive and Gram negative bacteria possessing antagonistic activity against other bacteria.
These AMPs can be potential candidates for alternative therapeutic agents against emerging multi-drug resistant infections including UTIs. Bacteriocins of Gram positive bacteria are classified into four groups on the basis of their size and mode of action $^{3}$. Class 1 baceteriocins are called lantibiotics contain thermostable peptides having molecular weight below $5 \mathrm{kDa}$. Class 2 groups include small $(<10 \mathrm{kDa})$, heat stable, nonlantibiotic containing bacteriocins which contain no lantionine. Class 3 bacteriocins include thermo labile bacteriocin having high molecular weight $(>30 \mathrm{kDa})$. Class 4 bacteriocins consist of glycoprotein (lactocin 27) or lipoprotein (lacstrepcins) that require non-protein moity for their activity ${ }^{4-7}$. Bacteriocins produced by Gram negative bacteria can be classified into two major groups, colicin and microcin, on the basis of their size ${ }^{8}$. Largest group of bacteriocin produced by Gram negative bacteria is Colicin (molecular weight 25-80 kDa). They are mainly synthesized by E.coli strains and also by Yersinia pestis, Serratia marcescens, Shigella, Klebsiellaand Pseudomonas ${ }^{9}$. Microsin, another group of bacteriocin produced by Gram negative bacteria are characterized by low molecular weight $(<10 \mathrm{kDa})$, thermostability and hydrophobicity ${ }^{10}$. Though hundreds of different types of bacteriocins have been discovered, only few have been allowed to be used as preservative or antibiotic due to concerns of toxicity and generation of hypersensitivity ${ }^{11}$. Studies 
on animal model revealed that bacteriocins like nisin, mersacidin and lacticin 3147 can be used as potent therapeutic agents ${ }^{12}$. Research on lantibiotics demonstrated that it has antagonistic activity against Strep. pneumoniae and MRSA in mice ${ }^{13}$, tooth diseases in $\operatorname{dogs}^{14}$ and bovine mastitis in dairy cows ${ }^{15}$. Besides, Salmonella infection in a mouse model has been drastically reduced by the bacteriocin microcin $\mathrm{J} 2^{16}$.

Due to the alarming surge of antibiotic resistance in uropathogens, development of novel antimicrobial agent against uropathogens has become an urgent need. Lactic acid bacteria (LAB) and their byproducts are considered to be safeby the U.S. Food and Drug Administration (FDA) ${ }^{17}$. Lactobacilli can produce various metabolic byproducts having inhibitory activity against pathogens including hydrogen peroxide, lactic acid and bacteriocins ${ }^{18}$. Being active in nanomolar range and nontoxic in nature, bacteriocins produced by lactic acid bacteria have attracted attention from many industries ${ }^{19}$. Lactobacilli have been found to be effective against catheter associated pathogens as they can displace the pathogens from catheter materials such as silicone rubber and can block binding of the pathogens to epithelial cells of urinary $\operatorname{tract}^{18}$. This study was designed to investigate antibacterial activity of bacteriocin like substances from Lactobacillus casei against multi-drug resistant bacteria isolated from urinary catheters. Our study indicates that the bacteriocin like substances used in our study can inhibit multi-drug resistant Shigella $s p$., Salmonella sp., Pseudomonas sp., E. coli and B. cereus.

\section{Materials and Methods}

Preparation of cell free supernatant (CFS) from Lactobacillus casei culture

One loopful of L.casei culture, isolated in a previous study in our laboratory ${ }^{20}$, was grown overnight in $10 \mathrm{ml}$ MRS broth at $37^{\circ} \mathrm{C}$ following the method as described by Al-Mathkhury et. $\mathrm{Al}^{21}$. Then $1 \mathrm{ml}$ of actively growing culture was inoculated into $500 \mathrm{ml}$ fresh MRS broth medium and incubated at $37^{\circ} \mathrm{C}$ for 24 hours under stationary condition. The cultured broth was centrifuged at $8,000 \mathrm{x}$ g for 20 minutes at $4^{\circ} \mathrm{C}$ (KUBOTA 6930, Japan). The supernatant was filtered through Whatman No.1 filter paper (pore size $0.11 \mu \mathrm{m}$ ) to remove residual cells and stored at $4^{\circ} \mathrm{C}$ until use ${ }^{22}$.

\section{Determination of Inhibitory activity of CFS on multi-drug resistant pathogenic bacteria}

The inhibitory activity was determined by agar-well diffusion method using sterilized and solidified Muellar-Hinton agar (MHA) (HiMedia, Mumbai, India) plates. The suspension of pathogen was prepared by inoculating 1 loopful of test organism (Staphylococcus aureus, Klebsiella pneumoniae, Proteus vulgaris, E.coli, Bacillus cereus, Pseudomonas aeruginosa, Shigella sp., Salmonella sp.) into $10 \mathrm{ml}$ sterile distilled water and turbidity was adjusted with $0.5 \mathrm{McF}$ arland Standard ${ }^{18-19}$. Suspension of the individual test organism was seeded homogenously on agar plates. Wells were made on the surface of solidified media with the help of sterile cork borer. One drop of melted agar was poured into each well and allowed to solidify to make a base layer. Then the wells were filled with $1001 / 4$ of CFS. The plates were kept at $4^{\circ} \mathrm{C}$ for 1 hour to allow maximum diffusion, followed by incubation at $37^{\circ} \mathrm{C}$ for 24 hours.

\section{Characterization of the inhibitory substance present in CFS}

The $\mathrm{pH}$ of CFS (pH 6) was checked. $100 \mu 1$ of CFS was added into one well in seeded Mueller Hinton plate. $\mathrm{pH}$ of remaining CFS was adjusted to $\mathrm{pH} 7.0$ with $1 \mathrm{M} \mathrm{NaOH}$ in order to rule out possible inhibition effects due to organic acids and filtered. A total of $100 \mu \mathrm{l}$ of $\mathrm{NaOH}$ treated CFS was added into another well. $4 \mathrm{ml}$ of neutralized CFS was then treated with $1 \mathrm{mg} / \mathrm{ml}$ of catalase (Merck, Germany) at $25^{\circ} \mathrm{C}$ for $30 \mathrm{~min}$ to eliminate the possible inhibitory action of $\mathrm{H}_{2} \mathrm{O}_{2}$ and filtered. Then $100 \mu \mathrm{l}$ of catalase treated CFS was added to a different well. Remaining catalase treated CFS was heated $121^{\circ} \mathrm{C}$ for 15 minutes and $100 \mu$ l of heat treated CFS was added to another well ${ }^{25}$. Zone of inhibition of observed after incubation at $37^{\circ} \mathrm{C}$ for 24 hours $^{25}$.

Effect of culture media on production of bacteriocin or bacteriocin like substances

To determine effect of culture media on production of bacteriocin or bacteriocin like substances three culture media media (MRS broth, LB broth and Nutrient Broth) were used to make CFS by following the same method describedin the previous sections. Antimicrobial activity of CFS of L.casei isolate were observed against test organisms following the same agar well diffusion method using CFS prepared from three different media.

Effect of incubation temperature on production of bacteriocin or bacteriocin like substances

CFS was prepared from L.casei by culturing in MRS broth at four different incubation temperatures $\left(27^{\circ} \mathrm{C}, 33^{\circ} \mathrm{C}, 37^{\circ} \mathrm{C}\right.$ and $40^{\circ} \mathrm{C}$ ) for 24 hours by following same method described in the previous section. Agar well diffusion method was used to investigate effect of temperature on the production of bacteriocin like substances by L.casei using same test organisms as mentioned in the previous section.

Effect of pH on production of bacteriocin or bacteriocin like substances

MRS broth was prepared, sterilized and the initial $\mathrm{pH}$ was measured which gave a reading of $\mathrm{pH} 6$. To reduce the $\mathrm{pH}$ to 4 and $5,1 \mathrm{M} \mathrm{HCl}$ was added to MRS broth separately and to increase the $\mathrm{pH} 1 \mathrm{M} \mathrm{NaOH}$ was used. $\mathrm{pH}$ meter (HANNAH $\mathrm{pH} 201$, Wisconsin, RI, USA) was used to adjust the $\mathrm{pH}$. Agar well diffusion method was used to check the antimicrobial activity of the CFS prepared from media with different $\mathrm{pH}$ values against the test organisms.

Effect of incubation period on production of bacteriocin or bacteriocin like substances

Three separate conical flasks containing $50 \mathrm{ml}$ sterilized MRS broth was inoculated with $100 \mu \mathrm{l}$ suspended fresh culture of 
L.casei followed by incubation at $37^{\circ} \mathrm{C}$ for 24,48 and 72 hours, respectively. Effect of incubation period on the antagonistic activity of CFS was observed against test organisms following agar well diffusion method.

\section{Results}

Inhibitory activity of CFS against multi-drug resistant pathogenic bacteria

In our study CFS from L. casei grown in MRS broth media was used to examine antimicrobial activity by agar well diffusion method against eight multi drug resistant pathogenic bacteria $(S$. aureus, K. pneumoniae, P. vulgaris, Shigella sp., Salmonella sp., Pseudomonas sp., E. coli and B. cereus) isolated in a previous study conducted in our laboratory ${ }^{31}$. These organisms showed multidrug resistance and biofilm forming capabilities in catheters of urinary tract infected patients. CFS was found to exhibit inhibitory activity against all the test organisms as shown in Table 1. Among the isolates, S. aureus and Pseudomonas sp. were found to show higher susceptibility to CFS as compared to other test organisms. Both Gram negative and Gram positive pathogens were found to produce zone of inhibition around the wells containing CFS. The results indicated that L. caseiused in our study produces antibacterial substances.

Table 1: Inhibitory activity of CFS from Lactobacillus casei against pathogenic bacteria determined by agar well diffusion method. The experiment was performed at least three times maintaining triplicates for each isolate. Zone of inhibition was measured and analyzed to determine mean and standard deviation (SD).

\begin{tabular}{lc}
\hline Isolates & $\begin{array}{c}\text { Zone of inhibition } \\
\text { (diameter in mm, Mean } \pm \text { SD) }\end{array}$ \\
\hline S. aureus & $21 \pm 1.5$ \\
K. pneumoniae & $19 \pm 2.5$ \\
P. vulgaris & $19 \pm 1.0$ \\
Salmonella sp. & $17 \pm 1.5$ \\
Shigella sp. & $18 \pm 1.5$ \\
Pseudomonas sp. & $21 \pm 1.0$ \\
B. cereus & $15 \pm 1.0$ \\
E. coli & $17 \pm 0.6$ \\
\hline
\end{tabular}

Characterization of the inhibitory substance(s) present in CFS

Lactic acid bacteria are known to produce organic acids and hydrogen peroxide to inhibit other competing microorganisms ${ }^{26}$. Both organic acids and hydrogen peroxide have antibacterial property and therefore these metabolites were neutralized to exclude the possibility that the antibacterial activity exhibited by CFS is not due to these antibacterial metabolites present in the CFS. CFS was treated first with $\mathrm{NaOH}$ to neutralize organic acids, followed by treatment with both catalase and $\mathrm{NaOH}$ to neutralize possible combined inhibitory actions by organic acids and hydrogen peroxide. No zone of inhibition was found around the well containing CFS neutralized with $\mathrm{NaOH}$ and catalase in case of Shigella sp, Salmonella sp, Pseudomonas sp, E. coli, and B. cereus (Figure 1). Out of eight isolates, only three isolates (P. vulgaris, $\mathrm{S}$. aureus, K. pneumoniae) were found to be sensitive to CFS after treating with $\mathrm{NaOH}$, but the activity of CFS significantly decreased after $\mathrm{NaOH}$ treatment. Further reduction of antagonistic activity was observed after treatment with catalase. Finally, proteins in the $\mathrm{CFS}$ were denatured by heating at $121^{\circ} \mathrm{C}$ for $15 \mathrm{~min}$ at $15 \mathrm{psi}$. The

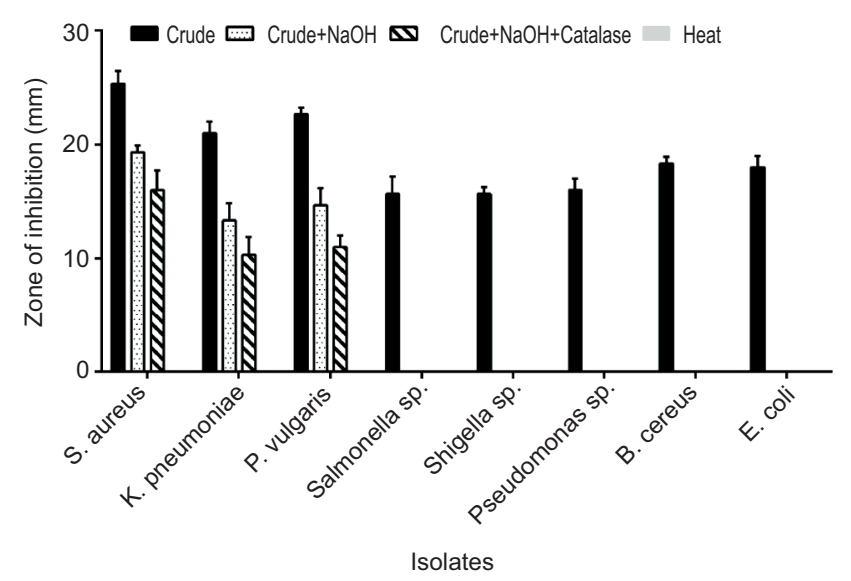

Figure 1. Zone of inhibition (in $\mathrm{mm}$ ) by crude $\mathrm{CFS}, \mathrm{NaOH}$ treated, both $\mathrm{NaOH}$ and Catalase treated and heat treated CFS against test organisms observed after incubation at 37ÚC for 24 hrs. in seeded Mueller Hinton agar plates (1001/4l CFS in each agar well). The experiment was done in triplicate for each isolate to obtain mean and standard deviation (SD).

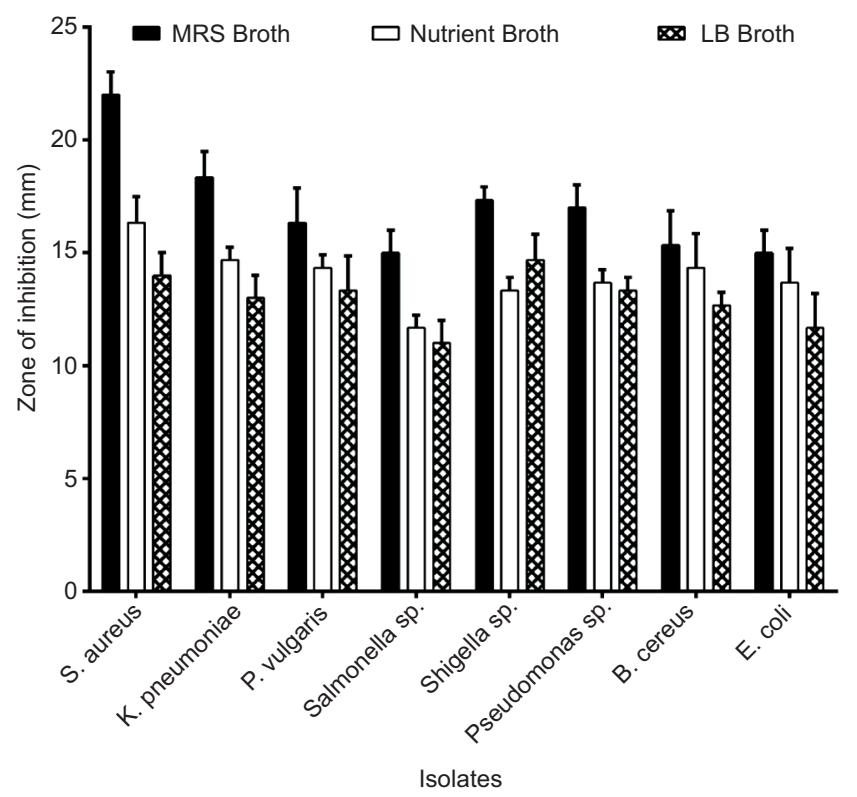

Figure 2. Comparison between the antibacterial activities (Zone of inhibition in $\mathrm{mm}$ ) of CFS from L.casei cultured in different media observed after incubation at 37ÚC for $24 \mathrm{hrs}$. in seeded Mueller Hinton agar plates (1001/4l CFS in each agar well). The experiment was done three times for each isolate to obtain mean and standard deviation (SD). 
antagonistic activity was completely destroyed against all eight isolates after heat treatment indicating that the inhibitory substances in the CFS are proteinaceous in nature (Figures 1). Based on these results we conclude that the inhibitory substances present in the CFS are proteinaeous in nature.

Effect of culture media, incubation temperature, incubation period and $\mathrm{pH}$ on antibacterial activity of the bacteriocin like substances

The CFS was further investigated to determine if culture media, incubation temperature, incubation period, and $\mathrm{pH}$ influence its antibacterial activity. It was found that CFS from MRS broth exhibited maximum inhibitory activity among the three media used in this study (Figure 2). CFS obtained from various temperature conditions were used against the selected organisms. CFS from the culture of L. casei incubated at $37^{\circ} \mathrm{C}$ exhibited the highest inhibitory activity among the temperatures examined in this study (Figure 3). The zone of inhibition gradually increased with the decrease of $\mathrm{pH}$ and highest antibacterial activity was observed at $\mathrm{pH} 4.0$ among the $\mathrm{pH}$ values examined in this study (Figure 4). We observed significant increase of inhibitory activity at $\mathrm{pH} 4.0$ as compared to that of $\mathrm{pH} 6.0$ against $S$. aureus, $K$. pneumoniae, $P$. vulgaris, Salmonella sp. and Shigella sp. Incubation period also affected the inhibitory activity. Optimum inhibitory activity of the crude supernatant was observed after 72 hours as judged by the zones of inhibition against the MDR bacteria (Figure 5). Significant increase of inhibitory activity was observed against S. aureus, K. pneumoniae and P. vulgaris at 72 hours as compared to those at 24 hours incubation (Figure 5). The results suggest that the inhibitory activity of bacteriocin like substances varies significantly with different cultural conditions like media, incubation temperature, $\mathrm{pH}$ and incubation time.

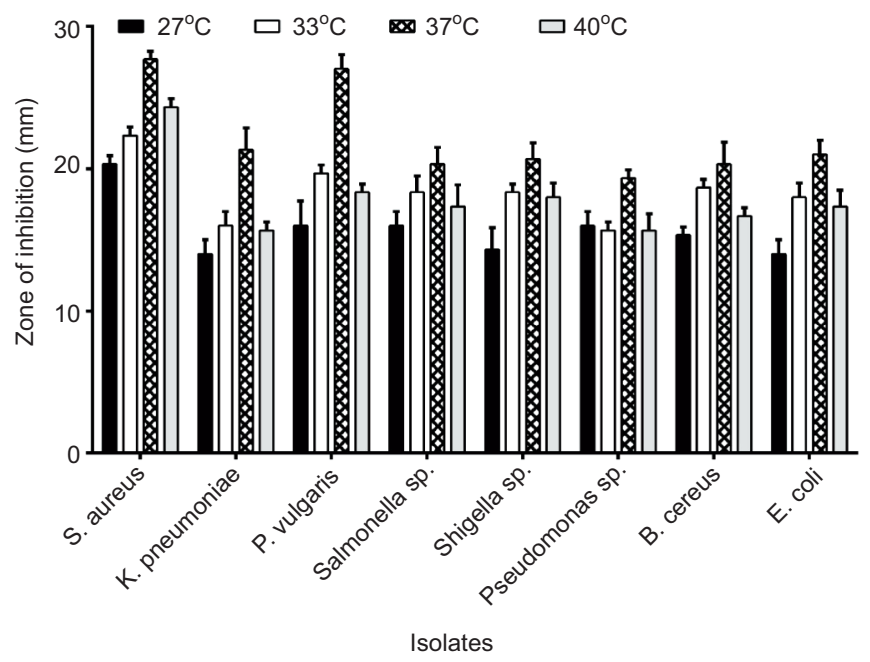

Figure 3. Comparison between the antibacterial activities (Zone of inhibition in $\mathrm{mm}$ ) of CFS from L.casei cultured at different incubation temperature. Zones of inhibition were observed following incubation at 37ÚC for 24 hrs. in seeded Mueller Hinton agar plates (1001/4l CFS in each agar well). This experiment was done three times for each isolate to obtain mean and standard deviation (SD).

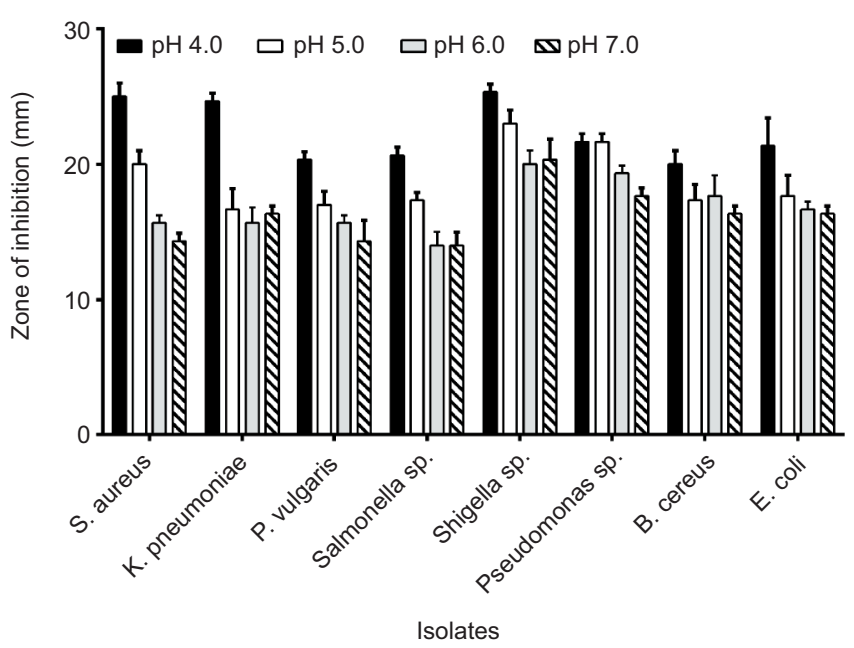

Figure 4. Comparison between the antibacterial activities of CFS (Zone of inhibition in $\mathrm{mm}$ ) from L.casei cultured at different pH against eight isolates. Zones of inhibition were observed following incubation at 37ÚC for 24 hrs. in seeded Mueller Hinton agar plates $\left(100^{1 / 4} \mathrm{lCFS}\right.$ in each agar well). The experiment was done in triplicate for each isolate to obtain mean and standard deviation (SD).

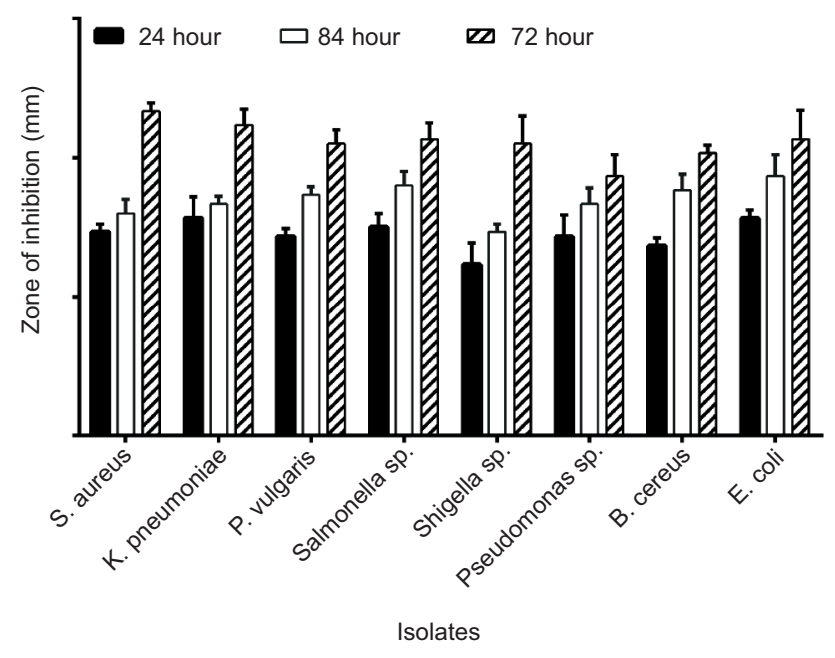

Figure 5. Comparison between the antibacterial activities of CFS (Zone of inhibition in $\mathrm{mm}$ ) from L. casei cultured at different incubation period against eight isolates. Zones of inhibition were observed following incubation at 37ÚC for 24 hrs. in seeded Mueller Hinton agar plates (1001/4l CFS in each agar well). This experiment was done in triplicate for each isolate to obtain mean and standard deviation (SD).

\section{Discussion}

We report here that bacteriocin like substances from $L$. caseican inhibit multidrug resistant bacteria isolated from urinary catheters. In addition to bacteriocin like substances, L.casei also produces other metabolites such as organic acids, and $\mathrm{H}_{2} \mathrm{O}_{2}$, which are inhibitory to other bacteria. Neutralization of these metabolites in the CFS led to reduced spectrum of inhibitory activity. After neutralization, five out of eight bacterial isolates (Shigella sp., 
Salmonella sp., Pseudomonas sp., E. coli and B. cereus) exhibited antibacterial activity. Three bacterial strains (P. vulgaris, $S$. aureus, and $K$. pneumoniae) exhibited no sensitivity to the neutralized CFS. Complete absence of antibacterial activity after heat treatment indicates that the antibacterial activity was due to proteinaceous substances, which were denatured or degraded after heat treatment. As bacteriocins are protein in nature, antibacterial activity of CFS can be attributed to the activity of bacteriocin or bacteriocin like substances 27,28 .

Optimum temperature for bacteriocin production from Lactobacillus sp., L. lactis, L. fermentum, L.casei and L. plantarum was reported to be $30^{\circ} \mathrm{C}^{22}$. It was also reported that zone of inhibition decreases with the increase of temperature above $30^{\circ} \mathrm{C}$. However, Scolari et al. reported that L.casei and Lactobacillus salivarius CRL 1328 produce bacteriocin optimally at $37^{\circ} \mathrm{C}^{29,30}$, which is consistent with our results. The discrepancy between our results and that of others is due to differences in strain background used. $\mathrm{pH}$ of the media was found to be important for antibacterial activity. For example, we observed decreased inhibitory activity with the increase of $\mathrm{pH}$, and the lowest activity was observed at $\mathrm{pH} 7.0$, which is consistent with the study of Tarelli et al. in which they reported that maximum bacteriocin production was found at $\mathrm{pH} 4.0$ to $5.0^{31}$. This $\mathrm{pH}$ tolerance is an extremely important feature since the isolates have the ability to survive, grow and produce bacteriocins under acidic and alkaline conditions. Optimum antibacterial activity of the CFS was observed after incubation of the L. casei for 72 hours. This result is consistent with the report of Onwuakor et al. and Karaoglu et al. which showed that incubation time affects bacteriocin production ${ }^{22,32}$.

We observed that five out of eight bacterial isolates were sensitive to bacteriocin like substances. We also observed that the bacteriocin like substance can inhibit both Gram positive ( $S$. aureus) and Gram negative bacteria ( $P$. vulgaris and $K$. pneumonia). This indicates that the target of this bacteriocin like substances are specific. Further investigation will provide the mode of action and the spectrum of bacterial species that can be inhibited.

\section{Conclusion}

Our resultsindicate that multi-drug resistant pathogenic bacteria can be inhibited by antibacterial substances from $L$. casei. The results also indicate that the antimicrobial substances responsible for inhibiting the bacterial pathogens are bacteriocin like substances (BLS). We found that different cultural conditions like types of media, incubation temperature, $\mathrm{pH}$ and incubation period had significant effects on the degree of inhibitory activity shown by bacteriocin like substances produced by $L$. casei. This is the first report showing inhibitory activity of bacteriocin like substances from Lactobacillus casei against multidrug resistant pathogens isolated from urinary catheters. Further investigation of these bacteriocin like substances might lead to an alternative of antibiotics against multi-drug resistant pathogenic bacteria.

\section{References}

1. Lodise T, Berger A, Altincatal A, Wang R, Bhagnani T, Gillard P \& Bonine NG. 2019. Antimicrobial Resistance or Delayed Appropriate TherapyDoes One Influence Outcomes More Than the Other among Patients with Serious Infections due to Carbapenem-Resistant Versus CarbapenemSusceptible Enterobacteriaceae?. Open Forum Infect Dis. 6(6): 194

2. Zowawi, Hosam M, Patrick NA Harris, Matthew J. Roberts, Paul A. Tambyah, Mark A. Schembri, M. Diletta Pezzani, Deborah A. Williamson, and David L. Paterson. 2015. "The emerging threat of multidrug-resistant Gram-negative bacteria in urology." Nature Reviews Urology. 12(10): 570 .

3. Klaenhammer TR. 1993. Genetics of bacteriocins produced by lactic acid bacteria. FEMS Microbiology Reviews.12(1-3): 39-85.

4. Kaur S and Kaur S. 2015. Bacteriocins as Potential Anticancer Agents. Frontiers In Pharmacology. 6: 272.

5. Kawai Y, Kemperman R, Kok J and Saito T. 2004. The circular bacteriocins gassericin A and circularin A. Current Protein and Peptide Science. 5(5): 393-398.

6. Joerger MC and Klaenhammer TR. 1986. Characterization and purification of helveticin $\mathrm{J}$ and evidence for a chromosomally determined bacteriocin produced by Lactobacillus helveticus 481. J. Bacteriol. 167(2): 439-446.

7. Oscáriz JC and Pisabarro AG. 2001. Classification and mode of action of membrane-active bacteriocins produced by gram-positive bacteria. International Microbiology. 4(1): 13-19.

8. Rebuffat S. 2011. Bacteriocins from Gram-Negative Bacteria: A Classification? In Prokaryotic Antimicrobial Peptides (Drider D and Rebuffat S eds), 55-72. Springer, New York, NY.

9. Cascales E, Buchanan SK, Duché D, Kleanthous C, Lloubes R, Postle, K, Riley M, Slatin S and Cavard D. 2007. Colicin biology. Microbiol. Mol. Biol. Rev. 71(1): 158-229.

10. Karpinski TM and Szkaradkiewicz AK. 2013. Characteristic of bacteriocines and their application. Pol. J. Microbiol. 62(3): 223-35.

11. Breukink E and de Kruijff B. 1999. The lantibiotic nisin, a special case or not?.Biochimica et Biophysica Acta (BBA) - Biomembranes. 1462(12): $223-234$.

12. Baindara P, Korpole S and Grover V. Bacteriocins: perspective for the development of novel anticancer drugs. 2018. Applied Microbiology and Biotechnology. 102(24): 10393-10408.

13. Goldstein BP, Wei J, Greenberg K and Novick R. 1998. Activity of nisin against Streptococcus pneumoniae, in vitro, and in a mouse infection model. J. Antimicrob. Chemother. 42(2): 277-278.

14. Howell T, Fiorellini J, Blackburn P, Projan S, Harpe J and Williams R. 1993. The effect of a mouthrinse based on nisin, a bacteriocin, on developing plaque and gingivitis in beagle dogs. J. Cli. Periodontol. 20(5): 335-9.

15. Twomey D, Wheelock A, Flynn J, Meaney W, Hill C and Ross R. 2000. Protection against Staphylococcus aureus mastitis in dairy cows using a bismuth-based teat seal containing the bacteriocin, lacticin 3147. J. Dairy Sci. 83(9): 1981-8.

16. Lopez FE, Vincent PA, Zenoff AM, Salomón RA and Farías RN. 2007. Efficacy of microcin J25 in biomatrices and in a mouse model of Salmonella infection. J. Antimicrob Chemother. 59(4): 676-680.

17. Doron, Shira and David R Snydman. 2015. Risk and safety of probiotics. Clinical Infectious Diseases. 60 (Suppl. 2): S129-S134.

18. Velraeds MM, van de Belt-Gritter B, Busscher HJ, Reid G and van der Mei HC. 2000. Inhibition of uropathogenic biofilm growth on silicone rubber in human urine by lactobacilli-a teleologic approach. World J. Urol. 18(6): 422-426. 
19. Parada JL, Caron CR, Medeiros ABP and Soccol CR. 2007. Bacteriocins from lactic acid bacteria: purification, properties and use as biopreservatives. Brazil. Arch. Biolo. Tech. 50(3): 512-542.

20. Kar S, Mahmud MN, Islam KN and Uddin MS. 2018. Antagonistic effect of bacteriocin like substances against biofilms formed by $P$. aeruginosa, K. pneumonia, and P. vulgaris. Int. Res. J. Biological Sci. 7(1): 1-5.

21. Al-Mathkhury HJF, Ali AS and Ghafil JA. 2011. Antagonistic effect of bacteriocin against urinary catheter associated Pseudomonas aeruginosa biofilm. North. Am. J. Med. Sci. 3(8): 367.

22. Onwuakor C, Nwaugo V, Nnadi C and Emetole J. 2014. Effect of Varied Culture Conditions on Crude Supernatant (Bacteriocin) Production from Four Lactobacillus Species Isolated from Locally Fermented Maize (Ogi). Am. J. Microbiol. Res. 2(5): 125-130.

23. Holder I and Boyce S. 1994. Agar well diffusion assay testing of bacterial susceptibility to various antimicrobials in concentrations non-toxic for human cells in culture. Burns. 20(5): 426-429.

24. Wiegand I, Hilpert K and Hancock RE. 2008. Agar and broth dilution methods to determine the minimal inhibitory concentration (MIC) of antimicrobial substances. Nat. Protocol. 3(2): 163-175.

25. Yang E, Fan L, Jiang Y, Doucette C and Fillmore S. 2012. Antimicrobial activity of bacteriocin-producing lactic acid bacteria isolated from cheeses and yogurts. AMB Express. 2(1): 1-12.

26. Hertzberger R, Arents J, Dekker HL, Pridmore RD, Gysler C, Kleerebezem $\mathrm{M}$ and de Mattos MJT. 2014. $\mathrm{H}_{2} \mathrm{O}_{2}$ Production in Species of the
Lactobacillus acidophilus Group: a Central Role for a Novel NADHDependent Flavin Reductase. Appl. Environ. Microbiol. 80(7): 2229-2239

27. Saadatzadeh A, Fazeli MR, Jamalifar H and Dinarvand R. 2013. Probiotic Properties of Lyophilized Cell Free Extract of Lactobacillus casei. Jundish. J. Nat. Pharmac. Pro. 8(3): 131-137.

28. Charlier C, Even S, Gautier M and Loir YL. 2018. Acidification is not involved in the early inhibition of Staphylococcus aureus growth by Lactococcus lactis in milk. Int. Dairy J. 18(2): 197-203.

29. Scolari G, Torriani S and Vescovo M. 1999. Partial characterization and plasmid linkage of a non proteinaceous antimicrobial compound in a Lactobacillus casei strain of vegetable origin. J. Appl. Microbiol. 86(4): 682-688.

30. Tomás J, Bru E, Wiese B, de Ruiz Holgado A and Macías MN. 2002. Influence of $\mathrm{pH}$, temperature and culture media on the growth and bacteriocin production by vaginal Lactobacillus salivarius CRL 1328. J. Appl. Microbiol. 93(4): 714-724.

31. Tarelli GT, Carminati D and Giraffa G. 1994. Production of bacteriocins active against Listeria monocytogenes and Listeria innocua from dairy enterococci. Food Microbiol. 11(3): 243-252.

32. Karaoglu Sa, Aydin F, Kiliç Ss and Kilic AO. 2003. Antimicrobial activity and characteristics of bacteriocins produced by vaginal lactobacilli. Turki. J. Med. Sci. 33(1): 7-13 